\title{
Detailed CFD Modelling and Simulation for Optimising Gas Flows in a Complex Duct Arrangement
}

\author{
Anupam $^{1}$, V Ramachandrarao Maddali ${ }^{1}$, Prateek Sharma ${ }^{1}$, Anil K popuri ${ }^{1}$, Ashutosh Saxena ${ }^{1}$, \\ B.N.Mohapatra ${ }^{1}$ \\ ${ }^{1}$ National Council for Cement And Building Materials \\ Ballabgarh, Faridabad, India \\ anupam@ncbindia.com;
}

\begin{abstract}
Computational simulation is known to be used for decades. One such platform known to be available for simulating the fluid dynamics (CFD) was used mostly in the field of Aeronautic, Space, Automotive or Electronics industries owing to its high cost, complexity and the low performance of computers. With the significant increase in computing power and reduction of equipment cost, the use of CFD is easily accessible and is gaining momentum significantly in the cement industry. This paper highlights the recent study done for a cement plant in western India. The plant is suffering severely with the pressurisation in complex ducting arrangement handling the flue gases. The cement plant is designed to produce 9000 tpd clinker from a single kiln with 3 string preheaters. The fan outlets of each string preheater is connected to a common junction duct (PH-junction duct) from which the gases are bifurcated to coal mill, raw mill and directly to the dust collector. The plant is also having another junction duct (Raw mill junction duct) for raw mill fan outlets.

These two junction ducts are connected by an Interconnecting duct. The operation team is experiencing huge pressurisation in the PHjunction duct and the interconnecting duct. The pressurization results in gases to come out from the openings in these ducts, which is not a healthy sign as these ducts are under negative pressure. The boundary conditions were measured by a team of process experts. The junction ducts along with its inlet and outlet ducts were modelled and simulated by using SST k-omega turbulent model.

The paper discusses, in detail, the finding of the simulation and the modifications suggested in the complex duct arrangement to solve the pressurization issues in the plant operation.
\end{abstract}

Keywords: PH-Junction duct, Raw mill junction duct, SST k- $\omega$, false air

\section{Nomenclature}

$\mathrm{CD}_{\mathrm{k} \omega}=$ positive portion of the cross-diffusion in $\omega$ - transport equation

$\mathrm{y}=$ distance from the field point to the nearest wall

$\alpha=$ damping coefficient

$\mathrm{t}=$ time

$\mathrm{S}=$ strain rate magnitude

$\mathrm{k}=$ kinetic energy of turbulence

$\mathrm{F} 1=$ blending function

$\mathrm{P}_{\mathrm{k}}=$ production of the kinetic energy of turbulence

$\mathrm{Uj}=$ mean velocity

$\beta, \beta^{*}, \sigma_{\mathrm{w} 2}=$ model constants

$\mathrm{x}_{\mathrm{i}}, \mathrm{x}_{\mathrm{j}}=$ Cartesian coordinates

$\omega=$ specific dissipation of turbulence kinetic energy

$\mathrm{v}=$ kinematic viscosity

$\mathrm{v}_{\mathrm{T}}=$ eddy viscosity

$\sigma \mathrm{k}=$ turbulent Schmidt number

\section{Introduction}

A cement plant in western part of India is suffering with pressurisation in complex ducting arrangement handling the flue gases. The cement plant is designed to produce 9000 tpd clinker from a single kiln with 3 string preheaters. The fan outlets of each string preheater is connected to a common junction duct (PH-junction duct) from which the gases are bifurcated to coal mill, raw mill and directly to the dust collector. The plant is also having another junction duct (Raw mill junction duct) for raw mill fan outlets.

These two junction ducts are connected by an Interconnecting duct. The operation team is experiencing huge pressurisation in the $\mathrm{PH}$-junction duct and the interconnecting duct. The pressurization results in gases to come out from the 
openings in these ducts, which is not a healthy sign as these ducts are under negative pressure. The plant entrusted NCB team for giving suitable solution to the problem using CFD. The boundary conditions such as temperature, pressure, gas velocities and gas composition were measured at on site by NCB team using different instruments such as manometer, S-type Pitot tube, gas analyser and digital temperature meter with $\mathrm{K}$ type thermocouple. These measured boundary condition were used for doing CFD simulation.

\section{Model description}

K-omega $(k-\omega)$ model is one of the most commonly used models. This include 2 additional transport equations to represent turbulent properties of flow - to account for history effects like convection and diffusion of turbulent energy. The transport variable $k$ determines the energy in turbulence and $\omega$ determines the scale of turbulence. The basic $k$ - $\omega$ model can be used for boundary layer problems, where the formulation works from the inner part through the viscous sub-layer, till the walls - hence the $k$ - $\omega S S T$ model can be used as a low Reynolds flow applications without extra damping functions. SST stands for Shear Stress Transport. The SST formulation also switches to a $k-\epsilon$ behaviour in the free-stream, which avoids that the $k$ $\omega$ problem that the model is very sensitive to the inlet free-stream turbulence properties.

Turbulence Kinetic Energy

$$
\frac{\partial k}{\partial t}+U_{j} \frac{\partial k}{\partial x_{j}}=P_{k}-\beta^{*} k \omega+\frac{\partial}{\partial x_{j}}\left[\left(\nu+\sigma_{k} \nu_{T}\right) \frac{\partial k}{\partial x_{j}}\right]
$$

Specific Dissipation Rate

$$
\frac{\partial \omega}{\partial t}+U_{j} \frac{\partial \omega}{\partial x_{j}}=\alpha S^{2}-\beta \omega^{2}+\frac{\partial}{\partial x_{j}}\left[\left(\nu+\sigma_{\omega} \nu_{T}\right) \frac{\partial \omega}{\partial x_{j}}\right]+2\left(1-F_{1}\right) \sigma_{\omega 2} \frac{1}{\omega} \frac{\partial k}{\partial x_{i}} \frac{\partial \omega}{\partial x_{i}}
$$

F1 (Blending Function)

$$
F_{1}=\tanh \left\{\left\{\min \left[\max \left(\frac{\sqrt{k}}{\beta^{*} \omega y}, \frac{500 \nu}{y^{2} \omega}\right), \frac{4 \sigma_{\omega 2} k}{C D_{k \omega} y^{2}}\right]\right\}^{4}\right\}
$$

Note: $\mathrm{F} 1=1$ inside the boundary layer and 0 in the free stream.

CDkw

$$
C D_{k w}=\max \left(2 \rho \sigma_{\omega 2} \frac{1}{\omega} \frac{\partial k}{\partial x_{i}} \frac{\partial \omega}{\partial x_{i}}, 10^{-10}\right)
$$

The $k-\omega S S T$ model also accounts for its good behavior in adverse pressure gradients and separating flow. The $k$ $\omega$ SST model does produce some large turbulence levels in regions with large normal strain, like stagnation regions and regions with strong acceleration. This effect is much less pronounced than with a normal $k$-€€ model though. The SST model has the ability to account for the transport of the principal shear stress in adverse pressure gradient boundary-layers.

\section{D Modelling and meshing}

The 3D model of junction duct has been created by using fluidyn CAD software. This is a complex duct arrangement with two junction ducts (PH junction duct and raw mill junction duct), 5 inlet ducts and 4 outlet ducts. 


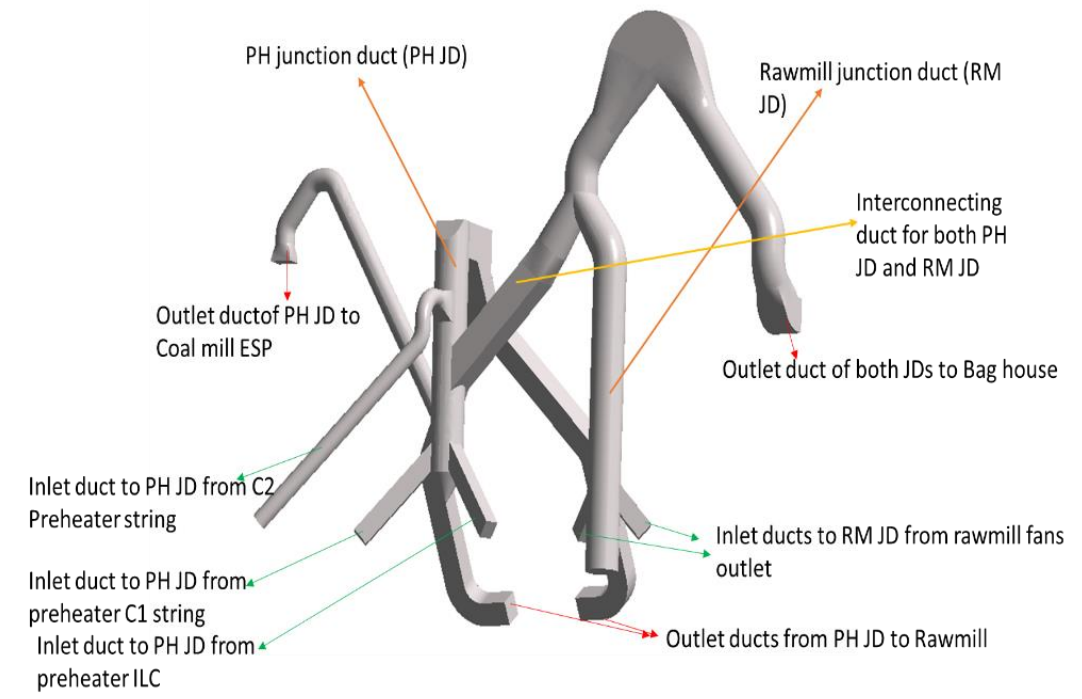

Figure 1: 3D modelling of complex junction ducts

In order to execute the mathematical solver on the flow field, the flow domain has to get discretized or meshed, that is, divided into small volumes. Generating a good quality mesh is a key step for obtaining a correct solution. The mesh type is unstructured mesh with 1106346 tetra elements.

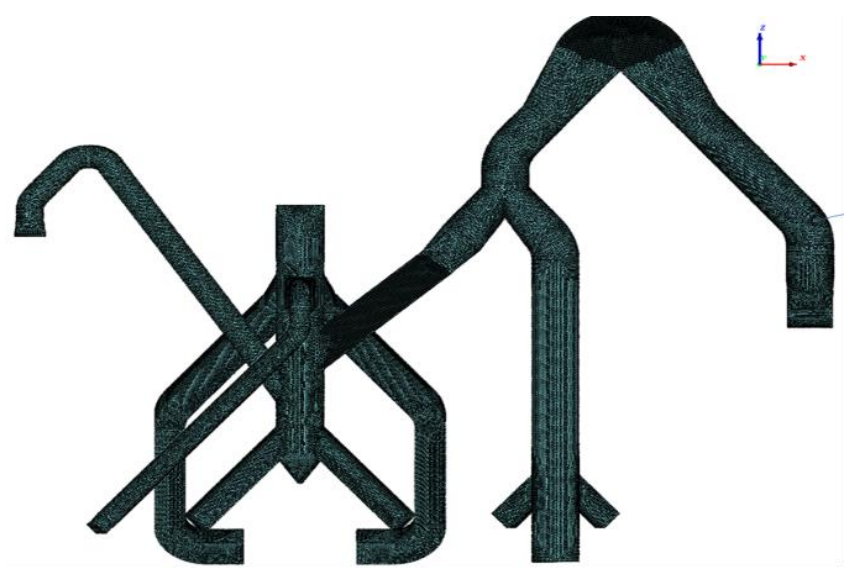

Figure 2: Meshing of Junction duct

\section{Turbulence Model}

The turbulence model selected for CFD simulation is Shear-Stress Transport (SST) k- $\omega$. The SST k- $\omega$ turbulence model is a two-equation eddy-viscosity model. The $\mathrm{k}-\omega$ models are suited for high Reynold numbers and include compressibility, shear flow spreading and they include some low Reynold number features.

Table 1: Turbulence model \& Other Conditions

\begin{tabular}{|l|l|}
\hline \multicolumn{2}{|c|}{ Turbulence model \& Other Conditions } \\
\hline Analysis type & Steady State \\
\hline Flow type & Incompressible, Turbulent flow \\
\hline Turbulence model & SST k-omega \\
\hline
\end{tabular}




\section{Solvers}

The equation for conservation of mass, the conservation of momentum and equation of conservation of energy are nonlinear so the solution will be obtained by an iteration process. The linearization in this iteration process can be done explicit or implicit. The implicit approach is unconditionally stable but takes more computation time, while the explicit approach is faster and requires less computation time. Hence, explicit method is selected for solving iterations for the discretization of the flow equations the second order upwind scheme will be used. For pressure velocity coupling SIMPLEC is used.

\section{Base Case Simulation}

The boundary conditions to CFD are given in table 2 below:

Table 2: Inlet and Outlet boundary conditions for base case

\begin{tabular}{|l|c|}
\hline \multicolumn{2}{|c|}{ Inlet Conditions (Gas inlet to junction duct) } \\
\hline $\mathrm{C} 1$ inlet & Temp: $559 \mathrm{~K}$, Speed: $32.8 \mathrm{~m} / \mathrm{s} \mathrm{O}_{2}: 4 \%, \mathrm{CO}_{2}: 27 \%$ \\
\hline $\mathrm{C} 2$ inlet & Temp: $520 \mathrm{~K}$, Speed: $24.31 \mathrm{~m} / \mathrm{s} \mathrm{O}_{2}: 3.4 \%, \mathrm{CO}_{2}: 27.5 \%$ \\
\hline IlC inlet & Temp: $524 \mathrm{~K}$, Speed: $29.13 \mathrm{~m} / \mathrm{s} \mathrm{O}_{2}: 7 \%, \mathrm{CO}_{2}: 27 \%$ \\
\hline Inlet from raw mill fan-1 & Temp: $357 \mathrm{~K}$, Speed: $29.76 \mathrm{~m} / \mathrm{s} \mathrm{O}_{2}: 10 \%, \mathrm{CO}_{2}: 20 \%$ \\
\hline Inlet from raw mill fan-2 & Temp: 357K, Speed: $29.76 \mathrm{~m} / \mathrm{s} \mathrm{O}_{2}: 10 \%, \mathrm{CO}_{2}: 20 \%$ \\
\hline Coal mill ESP & Outlet conditions (gas outlet to junction duct) \\
\hline Outlet to RABH & Press: 99862.71pa, Temp:541 k \\
\hline Outlet-1 to Rawmill & Press: 99862.71pa, Temp:374 k \\
\hline Outler-2 to raw mill & Press: 99038.95pa, Temp:541 k \\
\hline
\end{tabular}

\subsection{Results}

\section{a. Flow Pattern}

It was observed that part of gases coming from both rawmill fan outlets are going back to PH junction duct and obstructing the gases coming from junction duct leading to creation of turbulence in the ducts. This is due to low pulling force from baghouse fan (-14 mmWG RABH inlet and $-150 \mathrm{mmWG}$ at RABH fan inlet).

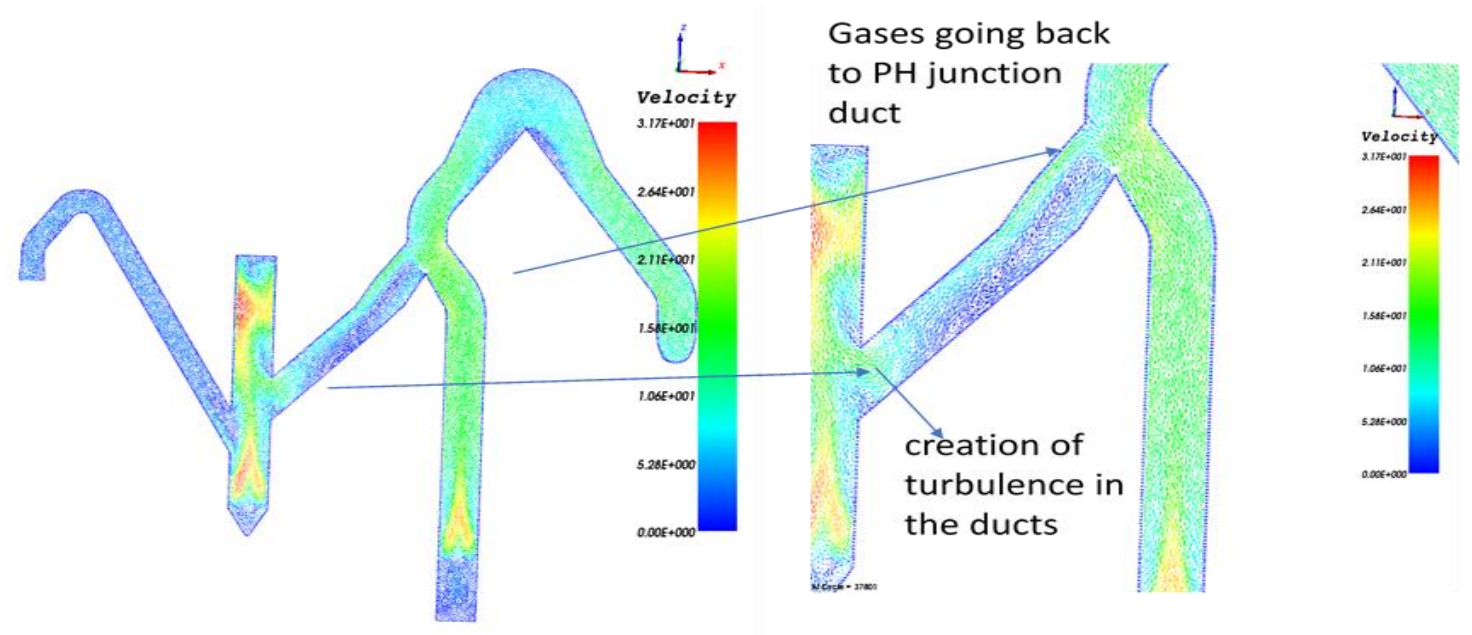

Figure 3: Gas flow pattern inside ducts for base case 


\section{b. Temperature Profile}

It can be interpreted from the temperature profile also that the gas temperature in the duct from $\mathrm{PH}$ junction duct to $\mathrm{RABH}$ is low $360 \mathrm{~K}$ indicating gases from raw mill fan are going to $\mathrm{PH}$ Junction duct.

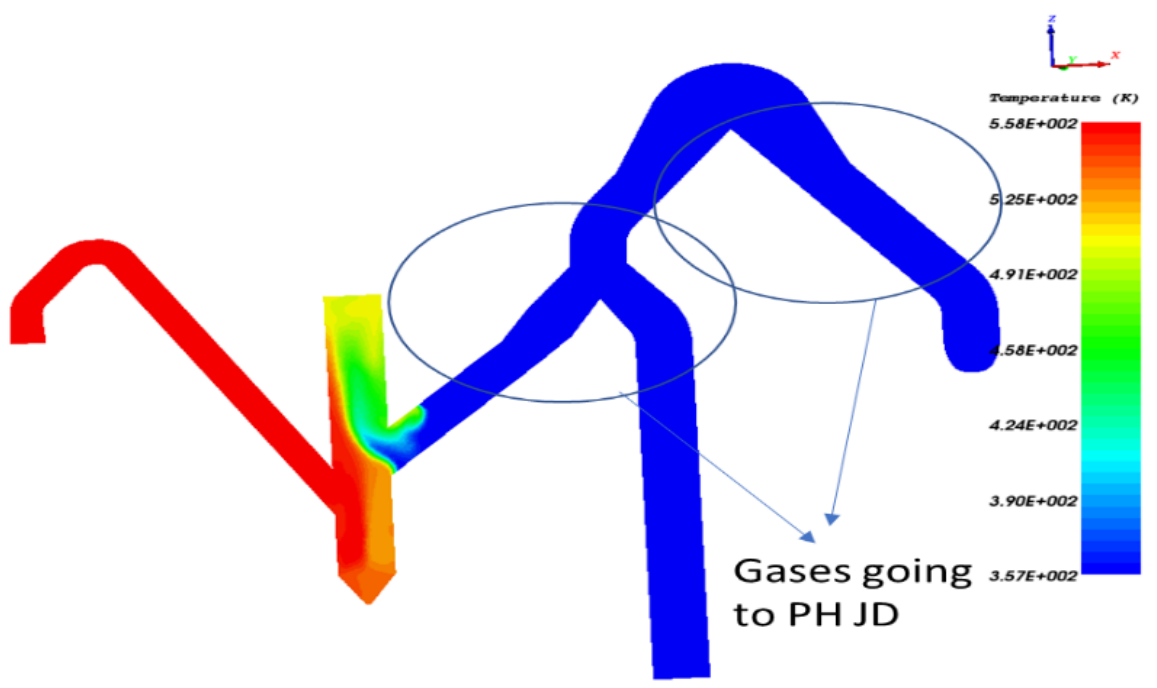

Figure 4: Base case temperature profile

\section{Modified Case Simulation}

Based on the results obtained from base case, to reduce turbulence inside the ducts and to avoid gases going from raw mill fan to PH junction duct, a modified case was simulated in the CFD.

As per the site measurements the false air across raw-mill circuit was $25 \%$ and false air across RABH was $17 \%$. Due to higher volumetric flow to the fan $(16 \mathrm{Lakh} \mathrm{m} 3 / \mathrm{hr})$ the static pressure at fan inlet from fan curve and site measurements is 99,850 Pa compared with the design flow of 1,400,000 m3/h @ 99,670 pa. The fan inlet pressure can be increased by reducing gas flow (false air) in the circuit.

Modified CFD simulation was done with reduced false air across raw mill circuit with raw mill fan outlet flow of $1,032,000 \mathrm{~m} 3 / \mathrm{h}$ to $919,000 \mathrm{~m} 3 / \mathrm{h}$ and reduced baghouse inlet pressure from $99,986 \mathrm{~Pa}$ to $99,950 \mathrm{~Pa}$ (assuming false air reduction across baghouse also).

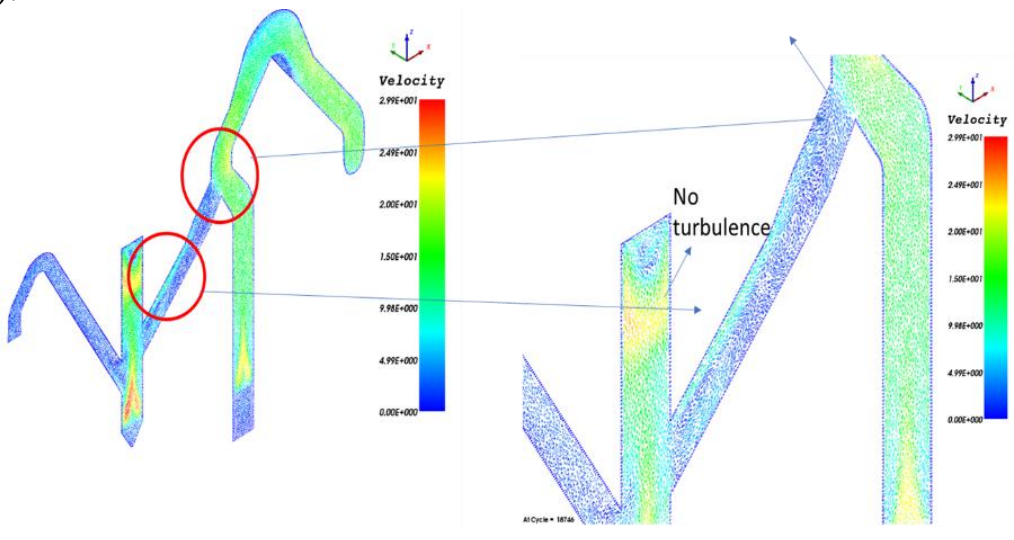

Figure 5: Gas flow pattern inside ducts for modified case with no turbulence 


\section{a. Temperature profile}

It was observed that from the above temperature profile in the modified case the gases from $\mathrm{PH}$ junction duct going to RABH with minimal turbulence

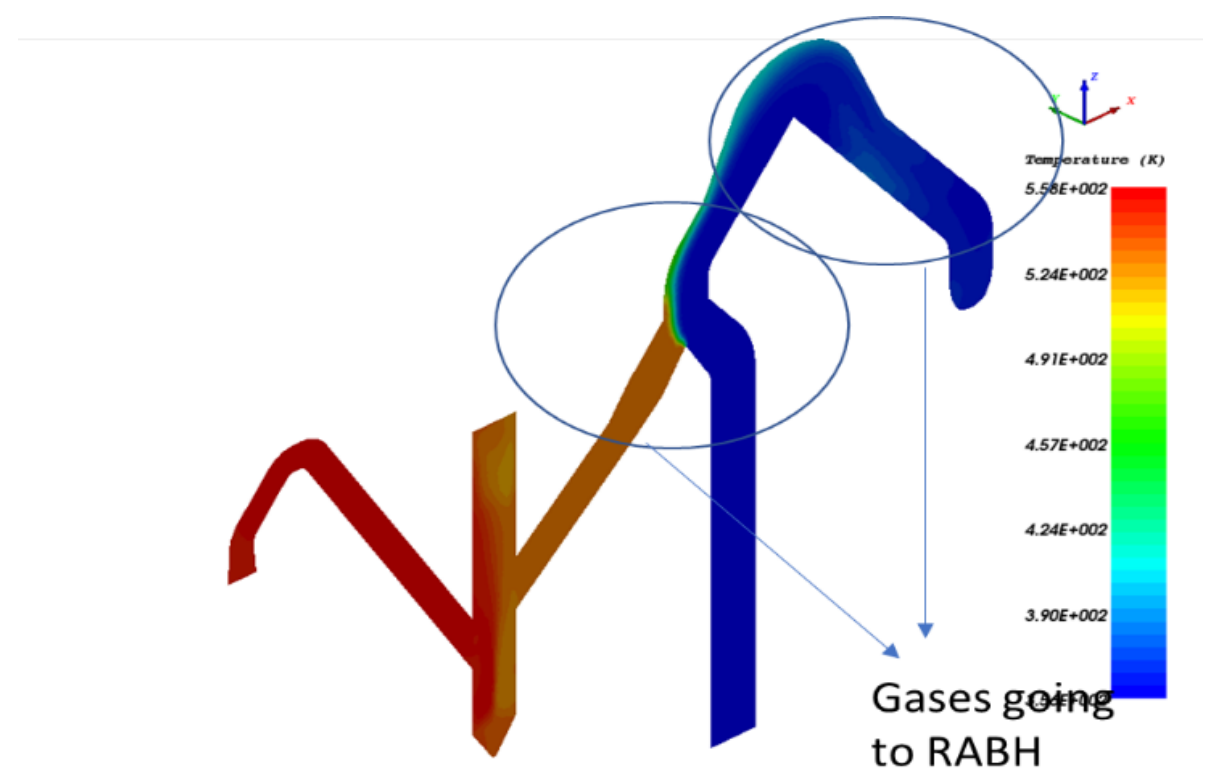

Figure 6: Modified case temperature profile showing gases going to RABH

\section{Conclusions}

It is concluded from the CFD study that the pressurization in Junction duct in base case simulation is happening due to reverse flow from RABH outlet to junction duct caused by higher gas flowrate from raw mill fan. The higher gas flowrate is indeed due to high amount of false air entering into the system. In the modified case when the circuit is simulated with reduced gas flowrate from raw mill fan the reverse flow of gas disappeared and gases from junction duct are going towards $\mathrm{RABH}$ outlet. Hence the pressurisation in junction duct is purely due to high ingress of false air in the system and unbalancing of pressures in the gas duct.

\section{Acknowledgements}

The authors would like to acknowledge support, technical inputs and encouragement from Mr. B.N.Mohapatra, Director General, National Council for Cement and Building Materials during different stages of the project.

\section{References}

[1] GOSMAN, A.D. IOANNIDES, E, Aspects of computer simulation of liquid-fuelled combustors. AIAA 81-0323, 1981.

[2] Gimbun, J., Chuah, T. G., Fakhru'l-Razi, A., and Thomas S. Y. Choong, Chem. Eng. Process (2004) (in press).

[3] NCCBM report on Process audit for Preheater and Junction Duct-2019, Faridabad,India. 